\title{
Infectious diseases: a brave new world
}

\author{
A symposium held on II June 2010 at the Royal College of Physicians \\ of Edinburgh \\ CL Mackintosh \\ Specialist Registrar, Infectious Diseases, The Brownlee Centre, Gartnavel General Hospital, Glasgow \\ and Monklands District General Hospital, Airdrie, Lanarkshire, UK
}

DECLARATION OF INTERESTS No conflict of interests declared.

\author{
Correspondence to CL Mackintosh, \\ The Brownlee Centre, \\ Gartnavel General Hospital, \\ 1053 Great Western Rd, \\ Glasgow GI 2 OYN, UK
}

tel. +44 (0) I4I 2 II 1095 e-mail c.mackintosh@talk2 I.com

\section{INTRODUCTION}

The threat posed by infectious diseases has, far from declining, evolved dramatically over the past 30 years. With emerging infections, established infections presenting with altered epidemiology and ancient re-emerging infections increasing in incidence, the challenges facing clinicians have never been greater.This, alongside rising antimicrobial resistance, changing demography of the UK population, increasing ease of travel, changes in lifestyle and a challenging economic climate, makes the need for new therapies, novel means of delivering care and accurate infectious disease epidemiological surveillance ever more pressing. This symposium highlighted how the practice of infectious diseases is meeting these challenges.

\section{SESSION I}

Dr Kitty Smith (Medical Lead in Travel Health Section, Health Protection Scotland) set the scene with an overview of the effect of migration and travel on the changing landscape of health in the UK. This was illustrated with tuberculosis (TB). Globally there has been a re-emergence of TB as a cause of massive morbidity and mortality. In the UK there has been a steady rise in the incidence of new cases of TB over the past ten years. In Scotland in 2009 there were 252 cases of TB - a $10 \%$ rise on 2007. The majority of these cases, $52 \%$, were in non-UK born individuals, a group more likely to suffer drug resistance.

Continuing the theme of emerging health threats, Dr Alisdair MacConnachie (Infectious Disease Consultant, Gartnavel General Hospital, Glasgow) gave a very personal account of being the physician responsible for the management of the first two cases of Influenza A (HINI) outside of the Americas and the difficulties such a scenario can pose; specifically, managing a public health scare of uncertain significance, staff anxiety and media involvement while maintaining optimal patient care. There was concern at the raft of alternative diagnoses, including various malignancies, as well as group A Streptococcus sepsis, dengue fever and Lemierre's syndrome, that were initially treated as influenza,' and hope was expressed that clinicians will continue to use clinical judgement first when assessing patients.
Dr Andrew Winter (Consultant in Sexual Health and HIV Medicine, The Sandyford Institute, Glasgow) talked with passion about an ancient foe which has recently re-emerged - syphilis. Since 1999 there has been a sustained rise in the number of cases identified in the UK, with 4,000 cases in 2007. Syphilis may be acquired through what is traditionally thought to be safe sex, and as such patients may not deem themselves at risk. It can present to any specialty with non-specific symptoms, including ulceration, rash and confusion, and thus can be missed. Although predominantly affecting men who have sex with men, it does affect heterosexual men and women and is commonly co-infected with other sexually transmitted infections.

\section{SESSION 2}

Considering TB, Dr Guy Thwaites (Wellcome Intermediate Clinical Fellow of Investigative Science, Imperial College London) gave a detailed overview of the evidence surrounding when to use corticosteroids. Taking each clinical entity of TB, he showed there exists evidence of benefit in pericardial TB and in TB meningitis, ${ }^{2,3}$ but not for pulmonary, endobronchial or pleural TB. It was noted that anecdotal evidence for benefit exists in life-threatening miliary or pulmonary TB. In human immunodeficiency virus-associated $T B$, although there is no evidence of harm, there is no clear evidence of benefit.

Professor John Halperin (Professor of Neurology, Mount Sinai School of Medicine, New York, USA) discussed nervous system Lyme disease - his expert review follows on page 248 .

\section{SESSION 3}

The escalating use of biological treatments for chronic diseases has the potential to significantly alter the spectrum of infectious diseases encountered in clinical practice.ProfessorThomas Evans (Professor of Molecular Microbiology, University of Glasgow) summarised the method of action of some of these agents, including those targeted to neutralise tumour necrosis factor alpha such as infliximab and etanarcept and those directed towards B cells such as rituximab. Although emphasising their effectiveness and safety, he highlighted the necessity for increased vigilance for infection-related 
adverse effects and screening where appropriate, in particular, pre-treatment screening for latent TB for those commencing an anti-tumour necrosis factor agent or hepatitis B for those on rituximab.

The remainder of the talks emphasised the importance of collaboration and multidisciplinary working in the provision of effective infection management. Dr Paul Chadwick (Consultant Microbiologist, Salford Royal Hospital) gave a clinical overview of his experience in the management of diabetic foot infection (DFI). Management of DFI should involve a multidisciplinary team, including microbiology, diabetology, vascular surgery, podiatry and radiology, an approach especially important when managing the one-third of patients with DFI who have evidence of osteomyelitis.

\section{SESSION 4}

The management of prosthetic joint infection (PJI) exemplifies the importance of multidisciplinary working. Dr Ivor Byren (Consultant in Infectious Diseases, Bone Infection Unit, Nuffield Orthopaedic Centre, Oxford) described the outcomes of patients with PJI managed by either a two-stage revision procedure with six weeks of intravenous antibiotics, or with debridement, antibiotics and implant retention (DAIR). Although there were differences in the characteristics of the patients receiving each procedure, the outcome in terms of the proportion living infection-free was the same. ${ }^{4}$

Finally, Dr Gavin Barlow (Infectious Disease Consultant, Hull and East Yorkshire Hospitals NHS Trust) described his experience of establishing an infectious diseases consultation service for bloodstream infections. It was stressed that these consultations are unsolicited and result in a change of antibiotic therapy in two-thirds of patients, with a significantly reduced proportion of patients being exposed to broad-spectrum antibiotics following the institution of this service. ${ }^{5}$

\section{TAKE-HOME MESSAGE}

Changing patterns of disease and our adaptation to these was the recurring theme of the meeting. The populations we serve are exposed, through travel, migration, changing habitat, new therapies and changing lifestyle choices, to rapidly altering and evolving infectious risks. These challenges make it essential that we find new and inventive ways of collaborating and pooling expertise in order to continue to ensure excellence in the care we give patients. This meeting highlighted new threats, old problems no longer gone or forgotten, and new approaches to established diseases.

\section{REFERENCES}

I Ho A, Fox R, Seaton RA et al. Hospitalised adult patients with Suspected 2009 HINI Infection at Regional Infectious Diseases Units in Scotland - most had alternative final diagnoses. J Infect 2010; 60:83-5. doi:I0.10I6/j.jinf.2009.II.00I

2 Prasad K, Singh MB. Corticosteroids for managing tuberculous meningitis. Cochrane Database Syst Rev 2008; I:CD002244.

3 Mayosi BM, Ntsekhe M,Volmink JA et al. Interventions for treating tuberculous pericarditis. Cochrane Database Syst Rev 2002; 4:CD000526.

4 Byren I, Bejon P,Atkins BL et al. One hundred and twelve infected arthroplasties treated with 'DAIR' (debridement, antibiotics and implant retention): antibiotic duration and outcome. J Antimicrobial Chemother 2009; 63:I264-7I. doi:I0.1093/jac/dkpl07

5 Lillie P, Moss P, Thaker $\mathrm{H}$ et al. Development, impact and outcomes of the Hull Bacteraemia Service. QJM 2008; 101:889-98.

\section{CONTINUING MEDICAL EDUCATION (CME)}

\section{Online distance learning and self-assessment from the RCPE}

To allow users to update their general medical knowledge, the online CME modules contain a variety of material, including articles, interactive cases and quizzes, webstreamed lectures and self-assessment multiple choice questions (MCQs). Each module also includes material of particular relevance to those undertaking core medical training.
CME modules are eligible for external distancelearning Continuing Professional Development (CPD) credits under the UK Federation of Royal Colleges of Physicians CPD scheme. To claim these credits you must take the MCQ test for the module (only available online). Full instructions are given with each module.
The College's online CME programme is available to Fellows, Collegiate Members, Associates and e-Associates. Log on to the Fellows' and Members' secure area at: http://www.rcpe.ac.uk. If you have forgotten your username or password please contact: webmaster@rcpe.ac.uk
Currently available for CPD points

- Cardiology

- Psychiatry

Coming soon

- Oncology

- Neurology

- Rheumatology 